\title{
Genetic and Phenotypic Variation of the Pepper golden mosaic virus Complex
}

\author{
J. K. Brown, A. M. Idris, K. M. Ostrow, N. Goldberg, R. French, and D. C. Stenger
}

First and second authors: Department of Plant Sciences, University of Arizona, Tucson 85721; third author: Howard Hughes Medical Institute, University of California, Los Angeles 90095; fourth author: Extension Plant Sciences Department, New Mexico State University, Las Cruces 88005; and fifth and sixth authors: U.S. Department of Agriculture-Agricultural Research Service and Department of Plant Pathology, University of Nebraska, Lincoln 68583.

Accepted for publication 27 June 2005.

\begin{abstract}
Brown, J. K., Idris, A. M., Ostrow, K. M., Goldberg, N., French, R., and Stenger, D. C. 2005. Genetic and phenotypic variation of the Pepper golden mosaic virus complex. Phytopathology 95:1217-1224.

Three isolates of the bipartite begomovirus Pepper golden mosaic virus (PepGMV) were characterized for genomic and biological properties. The complete nucleotide sequences of the DNA-A and DNA-B components were determined from infectious clones of PepGMV-Serrano (PepGMV-Ser), PepGMV-Mosaic (PepGMV-Mo), and PepGMV-Distortion (PepGMV-D). Nucleotide sequence identity among PepGMV components ranged from 91 to $96 \%$ for DNA-A and from 84 to $99 \%$ for DNA-B, with each PepGMV component most closely related to the corresponding component of Cabbage leaf curl virus (CaLCV). However, phylogenetic relationships among begomovirus components were incongruent because DNA-A of PepGMV and CaLCV share an inferred evolutionary history distinct from that of DNA-B. The cloned components of

PepGMV-Ser, -Mo, and -D were infectious by biolistic inoculation to pepper but differed in symptom expression: PepGMV-Ser exhibited a bright golden mosaic, PepGMV-Mo produced a yellow-green mosaic, and PepGMV-D caused only a mild mosaic and foliar distortion followed by a "recovery" phenotype in which leaves developing after initial symptom expression appeared normal. Differences in symptoms also were observed on tomato, tobacco, and Datura stramonium. Progeny virus derived from clones of PepGMV-Ser and -Mo were transmitted from pepper to pepper by the B biotype of Bemisia tabaci; progeny virus derived from PepGMV-D clones was not transmissible by the B biotype. Reassortant genomes derived from heterologous DNA components of the three isolates were infectious in all possible pairwise combinations, with symptom phenotype in pepper determined by the DNA-B component. Collectively, these results indicate that the three virus isolates examined may be considered distinct strains of PepGMV that have the capacity to exchange genetic material.
\end{abstract}

Since the 1970s, emergence of whitefly-transmitted begomoviruses causing significant disease of pepper, tomato, cucurbits, and bean in tropical and subtropical regions of the Americas has continued unabated $(2,3)$. This process was exacerbated by introduction of the polyphagous B biotype of Bemisia tabaci (Genn.) to the Americas in approximately 1986 to 1987, which has since displaced the endemic A biotype (4). Typically, the emergence of a new whitefly-transmitted disease of a crop prompted multiple reports from competing laboratories, with relationships among independent isolates often poorly defined. As a result, multiple synonyms were applied to isolates of a single virus species or, conversely, the same nomenclature applied to multiple species causing similar diseases. The confusion regarding relationships among begomovirus isolates infecting pepper in the Americas represents a typical case history.

Beginning in the late 1980s, epidemics of whitefly-transmitted begomoviral diseases of pepper (Capsicum annum L.) occurred in the southwestern United States, Mexico, the Caribbean, and Central America (5,9-11,15,17,20,24,27-29). "Serrano golden mosaic virus" from the Sonoran Desert of Arizona and Sinaloa, Mexico was among the first of these pepper-infecting begomoviruses to be described (9). Two phenotypically distinct begomoviruses causing leaf distortion (isolate D) or mosaic (isolate Mo) symp-

Corresponding author: J. K. Brown; E-mail address: jbrown@ Ag.arizona.edu

DOI: $10.1094 /$ PHYTO-95-1217

This article is in the public domain and not copyrightable. It may be freely reprinted with customary crediting of the source. The American Phytopathological Society, 2005 toms were isolated from a whitefly-infested greenhouse in south Texas and provisionally named "Texas pepper virus" (24). Two other begomovirus isolates ("Pepper huasteco virus" and "Pepper jalapeno virus") were recovered from pepper during severe epidemics of "rizado amarillo" disease occurring in Tamaulipas, Mexico during 1989 to 1993 (15). However, relationships among these begomovirus isolates remained unclear due to a lack of nucleotide sequence data and a variety of biological differences, including mechanical transmissibility, host range, and symptom phenotype. The situation was further confounded by contemporary isolation of several begomoviruses commonly found in tomato that also infect pepper $(5,6,8,23)$.

Since the initial descriptions of pepper-infecting begomoviruses in the Americas, relationships among the various isolates has been resolved partially by comparisons of DNA sequences. Complete nucleotide sequences of the DNA-A and DNA-B components of Pepper huasteco virus were determined (28) to be distinct from the other virus isolates described above. Pepper huasteco virus has since been renamed Pepper huasteco yellow vein virus (PHYVV) to conform with nomenclature rules (14) of the International Committee on Taxonomy of Virus (ICTV). The Pepper jalapeno virus complete DNA-A sequence was determined (27) and, based on a comparison with an $\approx 200$-nucleotide sequence of Texas pepper virus-D DNA-A (13), it was apparent that these two isolates represented the same species, such that Pepper jalapeno virus was renamed as "Texas pepper virus-Tam" (27). Another complete DNA-A sequence of an isolate of pepper from Costa Rica also was closely related and designated as "Texas pepper virus-CR" (20). More recently, the complete DNA B sequence of Texas pepper virus-Tam was determined (21). 
To resolve taxonomy and nomenclature issues, the ICTV has revised guidelines for begomovirus species demarcation. In the most recent incarnation (14), the ICTV guidelines use a rule-ofthumb value of $<89 \%$ nucleotide sequence identity threshold for DNA-A to define an isolate as a distinct begomovirus species. DNA-B nucleotide sequence identity is no longer considered a reliable indicator of species demarcation (14) due to the capacity of bipartite begomoviruses to undergo component reassortment or recombination $(7,16,18,19,22)$. The current ICTV guidelines further indicate that, for cases where the nucleotide sequence identity of DNA-A approaches the $89 \%$ threshold, biological properties also should be considered.

Based on the criteria described above, all isolates of Texas pepper virus and Serrano golden mosaic virus were considered synonymous and formally designated as a single virus species, Pepper golden mosaic virus (PepGMV). This recent decision by the ICTV (14) was based, in part, on our unpublished data. In this report, we describe the complete nucleotide sequences of PepGMV-Ser (formerly Serrano golden mosaic virus), PepGMVD (formerly Texas pepper virus-D), and PepGMV-Mo (formerly Texas pepper virus-Mo). We further utilized infectious clones of these three PepGMV isolates to assess genotypic and phenotypic variation within PepGMV and to determine viability of reassortant genomes in which noncognate components of the different isolates were paired.

\section{MATERIALS AND METHODS}

Virus isolates. PepGMV-D and PepGMV-Mo originally were isolated from 'Tabasco' pepper grown in a whitefly-infested greenhouse in Weslaco, TX in 1987 (24) and maintained as infectious DNA clones (PepGMV-D) or by whitefly transmission to jalapeno pepper (PepGMV-Mo). PepGMV-Ser was isolated from Serrano pepper grown in Sinaloa, Mexico in 1989 (9) and maintained in pepper by serial transfer using whiteflies or by biolistic bombardment (12).

Cloning and sequencing of PepGMV DNA components. Fulllength infectious clones of PepGMV-D DNA-A and DNA-B have been described (24) and were subcloned from the original plasmid vector pUC8 into pGEM7zf+ (Promega Corp., Madison, WI). The unit-length cloned insert of PepGMV-D DNA-A was subcloned into pGEM7zf+ as a Csp45I fragment excised from pTPV-E4-D1 (containing tandemly repeated EcoRI inserts of PepGMV-D DNAA) (24) and designated as pTPV-DA. The unit-length PepGMV-D DNA-B insert of pTPV-H1 (24) also was subcloned into pGEM7zf+ as a HindIII fragment and designated as pTPV-DB.

Full-length A and B DNA components of PepGMV-Mo and PepGMV-Ser were cloned into pGEM7zF+ using a procedure previously used to clone other bipartite begomovirus genomes $(7,8)$. Total DNA was extracted from pepper infected with each begomovirus isolate, digested with various restriction endonucleases, and analyzed by Southern hybridization using riboprobes of virion sense transcribed from pTPV-DA or pTPV-DB (data not shown). Restriction endonucleases which linearized doublestranded (ds)DNA of each component were used to digest an aliquot $(20$ to $50 \mu \mathrm{g}$ ) of total DNA extracted from each begomovirus isolate. Restriction endonuclease-digested total DNA samples were size selected $(\approx 2.4$ to $3.0 \mathrm{kbp})$ on a $1 \%$ agarose gel and recovered from the gel using the Gene Clean II kit (Bio 101, La Jolla, CA). Gel-purified DNAs were ligated to pGEM7zf+ (linearized with the appropriate restriction endonuclease) and used to transform Escherichia coli strain DH5af+. E. coli colonies harboring plasmids bearing PepGMV DNA inserts were identified by colony hybridization using virion-sense riboprobes transcribed from pTPV-DA or pTPV-DB. Plasmids bearing full-length inserts of PepGMV-Mo DNA-A (pTPV-MA) or DNA-B (pTPV-MB) and PepGMV-Ser DNA-A (pSGMV-X33) or DNA-B (pSGMV-H79) were arbitrarily selected for sequencing.
A series of nested deletions of each cloned begomovirus DNA insert was constructed in both directions using the Erase-a-Base kit (Promega Corp.). Plasmids cloned from the Erase-a-Base procedure were used as templates sequenced by the Iowa State University DNA Sequencing Facility. Sequences were compiled using the Sequencher 3.1 program (Gene Codes, Ann Arbor, MI) and analyzed for open reading frames (ORFs) using the DNA Inspector IIe program (Textco, West Lebanon, NH). Compiled nucleotide sequences for each begomovirus DNA component were deposited in GenBank with accession numbers listed in Table 1.

Phylogenetic analyses. Begomoviral reference sequences used for phylogenetic analyses were obtained from GenBank and included sequences of well-studied begomoviruses and other fulllength PepGMV component sequences (Table 1). Multiple sequence alignments of DNA-A/monopartite genomes or DNA-B were performed and genetic distance matrixes of all taxa compared were produced using CLUSTAL X 1.8 (26) with the output converted to percent nucleotide sequence identity ([1 - genetic distance $\times 100$ ).

Phylogenetic trees were reconstructed using the maximum parsimony (MP) algorithm available in PAUP* version $4.0 \mathrm{~b} 10$ (25). A most parsimonious tree was sought using a heuristic search method, stepwise addition, and the tree-bisection-reconnection random branch-swapping options, for 1,000 iterations of bootstrap sampling. Bootstrap values were calculated using the $\geq 70 \%$ confidence limits and placed at nodes on the most parsimonious tree. DNA-A and DNA-B trees were rooted using the bipartite African cassava mosaic virus (ACMV) from the eastern hemisphere as an outgroup.

Biolistic inoculation of cloned PepGMV genomes. Plasmids $(0.5 \mu \mathrm{g})$ bearing tandemly repeated copies of each PepGMV DNA component were constructed as described (24) and delivered to test plants using biolistic inoculation (12). Test plants included in host range studies were from the families Solanaceae (pepper cv. Anaheim, tomato [Lycopersicon esculentum L. cv. Humava], tobacco [Nicotiana tabacum L. cv. Samsun], and Datura stramonium L.), Lamiaceae (basil [Ocimum basilicum L. cv. Sweet]), Fabaceae (common bean [Phaseolus vulgaris L. cv. Red Kidney]), Malvaceae (cotton [Gossypium hirsutum L. cv. Delta]), and Cucurbitaceae (pumpkin [Cucurbita maxima Duchesne cv. Big Max]). Four seedlings (two- to three-leaf stage) of each test species were inoculated biolistically in each experiment, which was replicated a total of four times. Inoculated test plants were maintained in an insect-free growth chamber $\left(27^{\circ} \mathrm{C}\right.$, daily cycle of $12 \mathrm{~h}$ light and $12 \mathrm{~h}$ dark). Inoculated plants were monitored for the appearance of symptoms for 3 weeks. Infection status of plants was assessed by polymerase chain reaction (PCR) using primers that amplify a 576-bp fragment of the coat protein $(C P)$ gene (30) encoded by ORF AV1.

Whitefly transmission assays. Symptomatic 'Anaheim' pepper plants, infected following biolistic inoculation with the cloned components of PepGMV-D, -Mo, or -Ser, were used as source plants for whitefly transmission experiments with the B biotype of B. tabaci. Whiteflies (15 to 20 per plant) were given a $24-\mathrm{h}$ acquisition access period (AAP) on source plants followed by transfer to Anaheim pepper test plants for a 48-h inoculation access period (IAP). Inoculated plants were fumigated to kill whiteflies and maintained in a whitefly-free greenhouse. Test plants were monitored for the appearance of symptoms for 3 weeks. Vector transmission of virus to test plants was confirmed by PCR of the $C P$ gene as described above.

Component reassortment experiments. Plasmids $(0.5 \mu \mathrm{g})$ bearing tandemly repeated copies of each begomovirus DNA component were mixed together in all possible pairwise combinations of DNA-A and DNA-B. Viral clones were delivered to Anaheim pepper seedlings by biolistic inoculation and maintained in a whitefly-free growth chamber. Systemic virus infection in 
newly expanded, uninoculated leaves was confirmed by PCR of the $C P$ gene as described above.

\section{RESULTS}

Sequence annotation and distance analyses. The complete nucleotide sequences of cloned, full-length inserts of each DNAA and DNA-B component for PepGMV-D, PepGMV-Mo, and PepGMV-Ser were determined and deposited in GenBank (Table 1). The genome organization for all three PepGMV isolates (Fig. 1) was similar to that of other bipartite begomoviruses with DNAA encoding four conserved ORFs (AV1, AC1, AC2, and AC3) and DNA B encoding two conserved ORFs (BV1 and BC1). Several minor differences in genome organization were noted among the PepGMV isolates. ORF AC4 terminated at different positions in PepGMV-Ser and -Mo and was truncated relative to most other bipartite begomoviruses. PepGMV-D lacked ORF AC4. PepGMV-Ser ORF BC1 was larger in size relative to PepGMV-D and -Mo due to the presence of an in-frame methionine codon positioned upstream of the BC1 initiation codon of PepGMV-D and -Mo. Typical of bipartite begomoviruses, the PepGMV DNA$A$ and DNA-B components shared a common region (CR) sequence containing cis-acting elements of the origin of replication (ori) (1). CR sequences were identical for both components of a single isolate but varied in nucleotide sequence among PepGMV isolates by 4 to $24 \%$. Nonetheless, the Rep ( $\mathrm{AC} 1$ protein) binding site (GGAGTCCTGGAG) of the ori was identical for both components of all PepGMV isolates.

Distance analysis of DNA-A nucleotide sequences (Table 2) indicated that PepGMV-D, -Mo, -Ser, -Tam, and -CR were closely related strains sharing 91 to $96 \%$ nucleotide sequence identity. Distance analysis of the DNA-B component (Table 2) for PepGMV-D, -Mo, -Ser, and -Tam (no DNA-B sequence is available for PepGMV-CR) exhibited a broader range of nucleotide sequence identity (84 to 99\%). Compared with other begomoviruses, both genomic components of PepGMV were most closely related to Cabbage leaf curl virus (CaLCV) at 76 to $77 \%$ (DNA-A) and 55 to $57 \%$ (DNA-B) nucleotide sequence identity (Table 2).

Phylogenetic relationships. Maximum parsimony was used to examine relationships among PepGMV DNA-A or DNA-B components relative to other begomoviruses. The DNA-A component (Fig. 2) of five PepGMV isolates shared a common node exclusive of other begomoviruses and clustered with species of the Squash leaf curl virus (SLCV) clade, which includes begomoviruses isolated from cucurbits (SLCV, Squash mild leaf curl virus [SMLCV] and Cucurbit leaf curl virus [CuLCV]), bean (Bean calico mosaic virus [BCaMV]), cabbage (CaLCV), and cotton (Cotton leaf crumple virus [CLCrV]). The four sequenced PepGMV DNA-B components also shared a common node exclusive of all other begomovirus species examined (Fig. 3). Although both PepGMV DNA components shared a common node with the corresponding components of $\mathrm{CaLCV}$, inferred relation-

TABLE 1. Begomovirus taxa and GenBank accession numbers used in phylogenetic analyses

\begin{tabular}{|c|c|c|c|}
\hline \multirow[b]{2}{*}{ Virus } & \multirow[b]{2}{*}{ Acronym } & \multicolumn{2}{|c|}{ Accession number } \\
\hline & & DNA-A & DNA-Ba \\
\hline \multicolumn{4}{|l|}{ Pepper golden mosaic virus isolates } \\
\hline Pepper golden mosaic virus-Distortion & PepGMV-D & AY928514 & AY928515 \\
\hline Pepper golden mosaic virus-Mosaic & PepGMV-Mo & AY928512 & AY928513 \\
\hline Pepper golden mosaic virus-Serrano & PepGMV-Ser & AY928516 & AY928517 \\
\hline Pepper golden mosaic virus-Costa Rica & PepGMV-CR & AF149227 & NA \\
\hline Pepper golden mosaic virus-Tamaulipas & PepGMV-Tam & U57457 & AF499442 \\
\hline \multicolumn{4}{|l|}{ Other western hemisphere viruses } \\
\hline Abutilon mosaic virus & AbMV & U51137 & U51138 \\
\hline Bean calico mosaic virus & BCaMV & AF110189 & AF110190 \\
\hline Bean dwarf mosaic virus & BDMV & M88179 & M88180 \\
\hline Bean golden mosaic virus & BGMV & M88686 & M88687 \\
\hline Bean golden yellow mosaic virus-Mexico & BGYMV-MX & AF173555 & AF173556 \\
\hline Bean golden yellow mosaic virus-Puerto Rico & BGYMV-PR & M10070 & M10080 \\
\hline Cabbage leaf curl virus & CaLCV & U65529 & U65530 \\
\hline Chino del tomate virus & CdTV & AF226664 & AF226666 \\
\hline Pepper huasteco yellow vein virus & PHYVV & X70418 & X70419 \\
\hline Potato yellow mosaic Panama virus & PYMPV & Y15034 & Y15033 \\
\hline Potato yellow mosaic virus & PYMV & D00940 & D00941 \\
\hline Potato yellow mosaic virus-Trinidad and Tobago & PYMV-TT & AF039031 & AF039032 \\
\hline Rhynchosia golden mosaic virus & RhGMV & AF239671 & NA \\
\hline Sida golden mosaic virus & SiGMV & AF049336 & AF039841 \\
\hline Sida golden mosaic Costa Rica virus & SiGMCRV & X99550 & X99551 \\
\hline Sida golden mosaic Honduras virus & SiGMHV & Y11097 & Y11098 \\
\hline Sida yellow vein virus & SiYVV & Y11099 & Y11100 \\
\hline Squash leaf curl virus & SLCV & M38183 & M38182 \\
\hline Squash mild leaf curl virus & SMLCV & AF421552 & AF421553 \\
\hline Tomato golden mosaic virus & TGMV & K02029 & K02030 \\
\hline Tomato rugose mosaic virus & ToRMV & AF291705 & AF291706 \\
\hline Tomato mottle Havana virus-Quivican & ToMHV-Qui & Y14874 & Y14875 \\
\hline Tomato mottle Taino virus & ToMoTV & AF012300 & AF012301 \\
\hline Tomato mottle virus & ToMoV & L14460 & L14461 \\
\hline \multicolumn{4}{|l|}{ Eastern hemisphere viruses } \\
\hline African cassava mosaic virus-Kenya & ACMV-KE & J02057 & J02058 \\
\hline African cassava mosaic virus-Nigeria & ACMV-NG & X17095 & X17096 \\
\hline Ageratum yellow vein virus & AYVV & X74516 & NB \\
\hline Tomato leaf curl Taiwan virus & ToLCTWV & U88692 & NB \\
\hline Tomato leaf curl virus & ToLCV & S53251 & NB \\
\hline Tomato yellow leaf curl Sardinia virus & TYLCSV & X61153 & NB \\
\hline Tomato yellow leaf curl Sardinia virus-Sicily & TYLCSV-Sic & $\mathrm{Z} 28390$ & NB \\
\hline Tomato yellow leaf curl Thailand virus & TYLCTHV & X63015 & X63016 \\
\hline Tomato yellow leaf curl virus & TYLCV & X15656 & NB \\
\hline
\end{tabular}

${ }^{a} \mathrm{NA}=$ DNA-B sequence not available; $\mathrm{NB}=$ monopartite virus has no DNA-B. 
ships of DNA-A and DNA-B were incongruent in that the DNA-B component of these two viruses clustered with PHYVV rather than with species of the SLCV clade (Figs. 2 and 3).

Biological properties of cloned PepGMV genomes. Cognate pairs of cloned DNA-A and -B components for each of the three PepGMV isolates were infectious upon biolistic inoculation to four species of the Solanaceae (Table 3). Each cloned PepGMV isolate exhibited distinct symptoms in Anaheim pepper (Fig. 4, Table 3). PepGMV-D was unique among the isolates in that in-
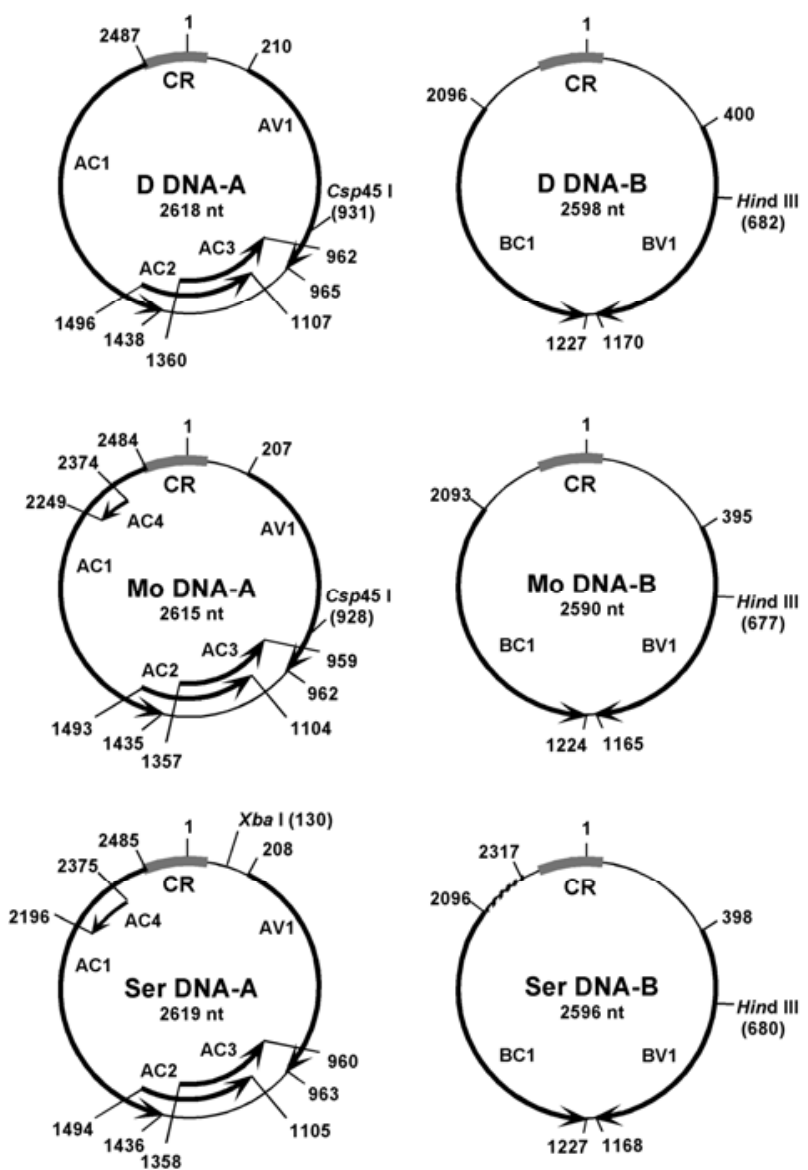

Fig. 1. Genome organization maps of three Pepper golden mosaic virus (PepGMV) strains. Circular maps show the DNA-A and DNA-B components for the distortion (D), mosaic (Mo), and Serrano (Ser) strains of PepGMV. Arrows denote location and polarity of open reading frames; gray arc denotes location of common region (CR) sequences shared among cognate components. Hatched arc denotes portion of open reading frame $\mathrm{BC} 1$ unique to PepGMV-Ser DNA-B. Nucleotide coordinates are for the virion-sense strand with nucleotide 1 defined as the A residue immediately $3^{\prime}$ of the strandspecific Rep (AC1 protein) nick site within the origin of DNA replication. Restriction endonuclease sites used to clone each full-length component are indicated with nucleotide coordinates in parentheses. fected pepper plants underwent a recovery phenotype with new growth asymptomatic but still containing virus as determined by PCR (data not shown). However, systemic infection of $D$. stramonium, tobacco, and tomato with PepGMV-D resulted in persistent systemic symptoms (Table 4) as also seen in PepGMVD-infected $N$. benthamiana Domin. (23). Differences in symptom phenotype among the three cloned PepGMV isolates also were observed in tomato, tobacco, and D. stramonium (Table 4). Test species representing four other plant families did not exhibit symptoms following biolistic inoculation (Tables 3 and 4) and PCR assays of noninoculated leaves of test plants were negative for begomovirus infection (data not shown).

Biolistically inoculated pepper seedlings infected with each cloned PepGMV isolate were used as source plants for whitefly transmission assays. Progeny virus of PepGMV-Mo or PepGMVSer were readily transmitted by the B biotype from pepper to pepper (Table 5). In contrast, no vector transmission of progeny virus derived from cloned DNAs of PepGMV-D was observed. Systemic infection of test plants was verified by detecting viral genome in total DNA isolated from new leaves using PCR (data not shown).

Reassortment assays were conducted with all possible heterologous combinations of cloned PepGMV DNA components (Table 6). All six reassortants were able to induce systemic infection of pepper following biolistic inoculation. Symptom expression varied, depending on the pairing of heterologous components (Table 6; Fig. 4). Reassortants composed of PepGMV-D DNA-B and DNAA of PepGMV-Ser or -Mo displayed mild mosaic and leaf curl symptoms followed by recovery similar to that produced by the cognate pair of PepGMV-D components. In contrast, reassortants in which the DNA-B of PepGMV-Ser or PepGMV-Mo was paired with a heterologous DNA-A component resulted in more severe mosaic, leaf-curling, and vein-clearing symptoms.

\section{DISCUSSION}

Texas pepper virus and Serrano golden mosaic virus are synonymous with PepGMV. The five PepGMV DNA-A components share 91 to $96 \%$ nucleotide sequence identity, a range above the ICTV species demarcation threshold of $89 \%$. In contrast, the four PepGMV DNA-B components exhibited a wider range of nucleotide sequence diversity ( 84 to $99 \%$ ), but this is a common situation among strains of bipartite begomoviruses. The three PepGMV isolates examined in this work share a similar host range and were able to form viable reassortants. Although the isolates differed from one another in symptom phenotype and vector transmissibility, such variation is not unusual among strains of a virus. Collectively, both genotypic and phenotypic comparisons indicated that the begomovirus isolates examined here and formerly known as Texas pepper virus and Serrano golden mosaic virus are appropriately designated as strains of PepGMV.

Incongruent phylogenetic relationships of PepGMV components infer distinct evolutionary histories. The DNA-A com-

TABLE 2. Nucleotide sequence identity of Pepper golden mosaic virus (PepGMV) isolates -Ser, -Mo, and -D with other sequenced isolates of PepGMV (-Tam and $-\mathrm{CR}$ ) and three closely related begomoviruses (Bean calico mosaic virus [BCaMV]), Cabbage leaf curl virus [CaLCV[), and Squash leaf curl virus [SLCV])

\begin{tabular}{|c|c|c|c|c|c|c|}
\hline \multirow[b]{2}{*}{ Virus } & \multicolumn{2}{|c|}{ PepGMV-D } & \multicolumn{2}{|c|}{ PepGMV-Mo } & \multicolumn{2}{|c|}{ PepGMV-Ser } \\
\hline & DNA-A & DNA-B & DNA-A & DNA-B & DNA-A & DNA-B \\
\hline PepGMV-D & 100 & 100 & 94 & 88 & 92 & 84 \\
\hline PepGMV-Mo & 94 & 88 & 100 & 100 & 92 & 87 \\
\hline PepGMV-Tam & 94 & 99 & 95 & 87 & 91 & 84 \\
\hline PepGMV-CR & 91 & $\mathrm{NA}^{\mathrm{a}}$ & 91 & NA & 96 & NA \\
\hline BCaMV & 71 & 47 & 70 & 48 & 71 & 47 \\
\hline
\end{tabular}

${ }^{a}$ NA $=$ DNA-B sequence not available. 
ponent phylogeny clearly indicates that PepGMV and CaLCV share common ancestry with other members of the SLCV clade. In contrast, the DNA-B component of PepGMV and CaLCV share a common ancestor with PHYVV, a virus that has a DNA-A component only distantly related to the SLCV clade. Recently, Méndez-Lozano et al. (21) reported similar results but did not present or specify the type of phylogenetic analyses conducted. Incongruent component phylogenies imply that the common ancestor of PepGMV and CaLCV arose through component re- assortment with an ancestor of PHYVV. That cognate components of both CaLCV and PepGMV CR share high nucleotide sequence identity further suggests that the common ancestor of these two viruses also may have undergone recombination, such that cis-acting elements of the two DNA components were compatible. The simplest, but not necessarily actual, path of evolution would have been for an SLCV clade-like ancestral DNA-A to have encountered a heterologous PHYVV-like ancestral DNA-B in a mixed infection in a common host and, through recombi-

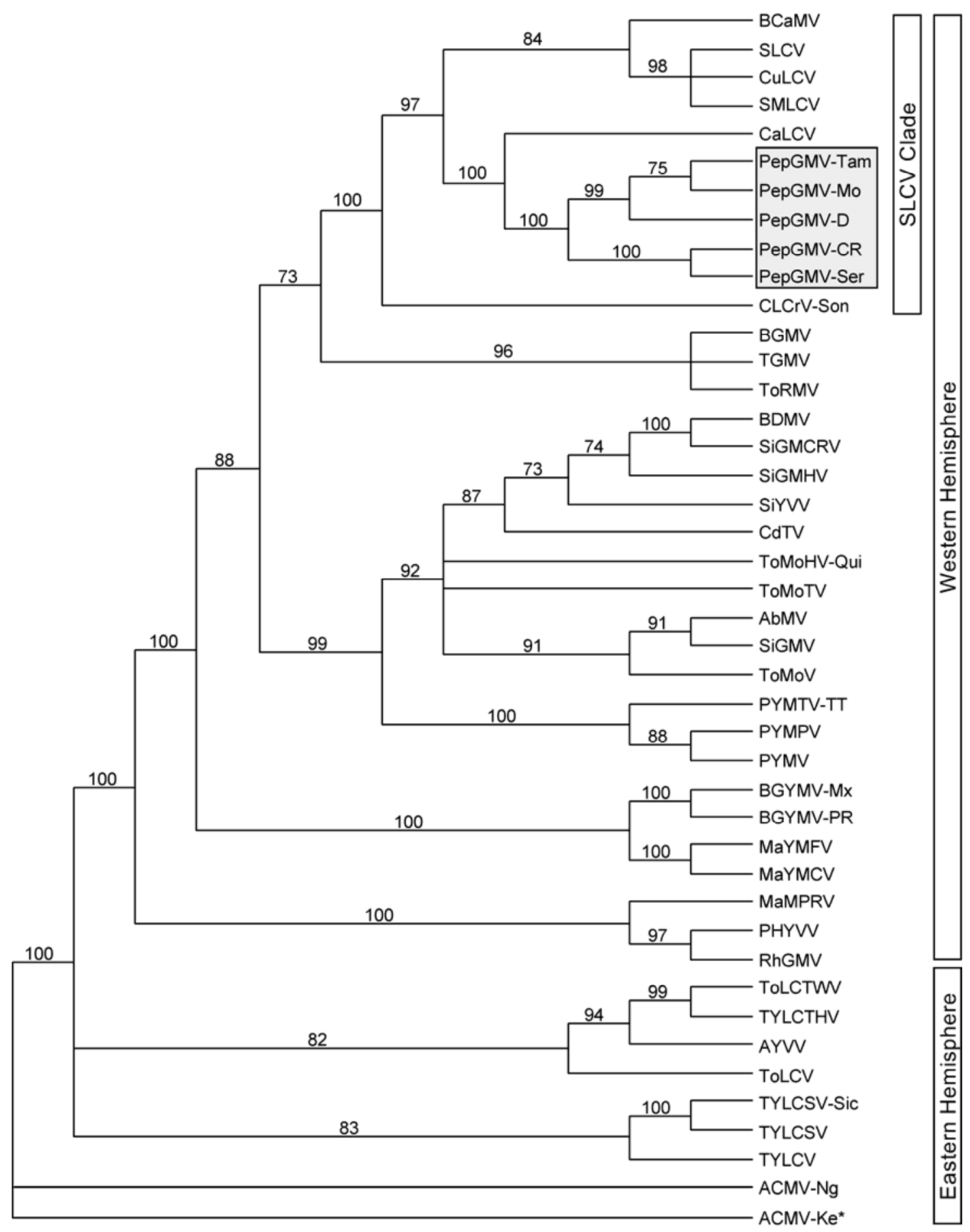

Fig. 2. Phylogenetic relationships among begomovirus DNA-A components. Presented is a maximum parsimony tree based on 1,000 iterations. Bootstrap values are indicated for nodes having $\geq 70 \%$ confidence; nodes with bootstrap values $<70 \%$ were collapsed to polytomies. Placement of five Pepper golden mosaic virus (PepGMV) DNA-A components is highlighted with a gray box. Geographic origin (western or eastern hemisphere) of begomoviruses is indicated on the right. Viruses of the Squash leaf curl virus (SLCV) clade are indicated on the right. Vertical and horizontal branch lengths are arbitrary; only tree topology is relevant. The tree was rooted using the bipartite African cassava mosaic virus (ACMV) from the eastern hemisphere as an outgroup (*). Acronyms for begomoviruses are defined in Table 1. 


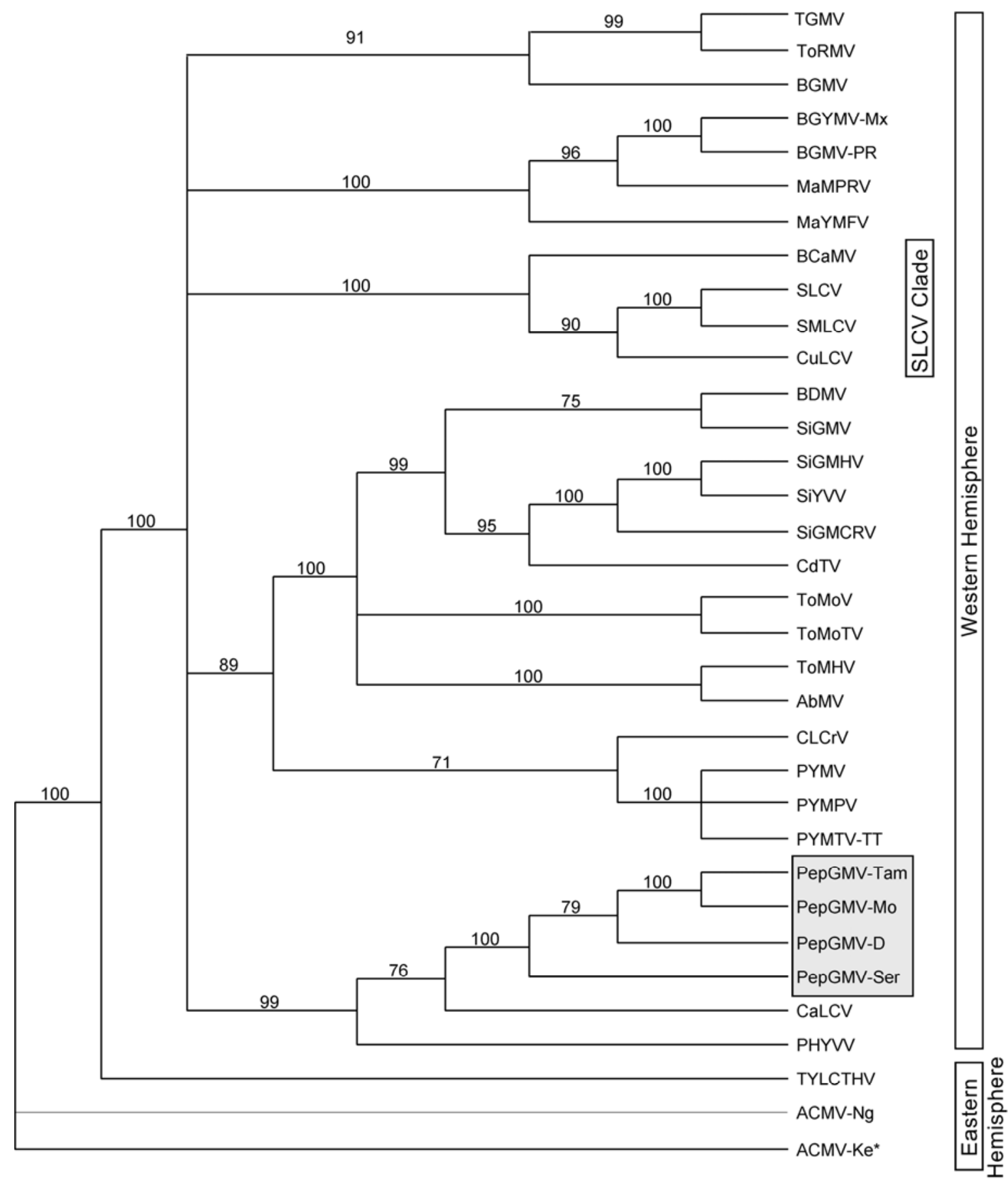

Fig. 3. Phylogenetic relationships among begomovirus DNA-B components. Presented is a maximum parsimony tree based on 1,000 iterations. Bootstrap values are indicated for nodes having $\geq 70 \%$ confidence; nodes with bootstrap values $<70 \%$ were collapsed to polytomies. Placement of four Pepper golden mosaic virus (PepGMV) DNA-B components is highlighted with a gray box. Geographic origin (western or eastern hemisphere) of begomoviruses is indicated on the right. Viruses of the Squash leaf curl virus (SLCV) clade are indicated on the right. Vertical and horizontal branch lengths are arbitrary; only tree topology is relevant. The tree was rooted using the bipartite African cassava mosaic virus (ACMV) from the eastern hemisphere as an outgroup (*). Acronyms for begomoviruses are defined in Table 1.

TABLE 3. Experimental host range of cloned Pepper golden mosaic virus (PepGMV) isolates -Ser, -Mo, and -Da

\begin{tabular}{lcccccccc}
\hline PepGMV isolate & Datura stramonium & Pepper & Tobacco & Tomato & Basil & Bean & Cotton & Pumpkin \\
\hline Ser & $10 / 16$ & $14 / 16$ & $15 / 16$ & $13 / 16$ & $0 / 16$ & $0 / 16$ & $0 / 16$ \\
Mo & $11 / 16$ & $16 / 16$ & $12 / 16$ & $14 / 16$ & $0 / 16$ & $0 / 16$ & $0 / 16$ \\
D & $13 / 16$ & $11 / 16$ & $11 / 16$ & $14 / 16$ & $0 / 16$ & $0 / 16$ & $0 / 16$ & $0 / 16$ \\
\hline
\end{tabular}

a A single experiment used four plants of each host species per isolate; data presented are the combined totals of four replicate experiments. Numerator indicates number of plants systemically infected and denominator indicates number of plants biolistically inoculated with mixtures of cloned cognate components of each isolate. 

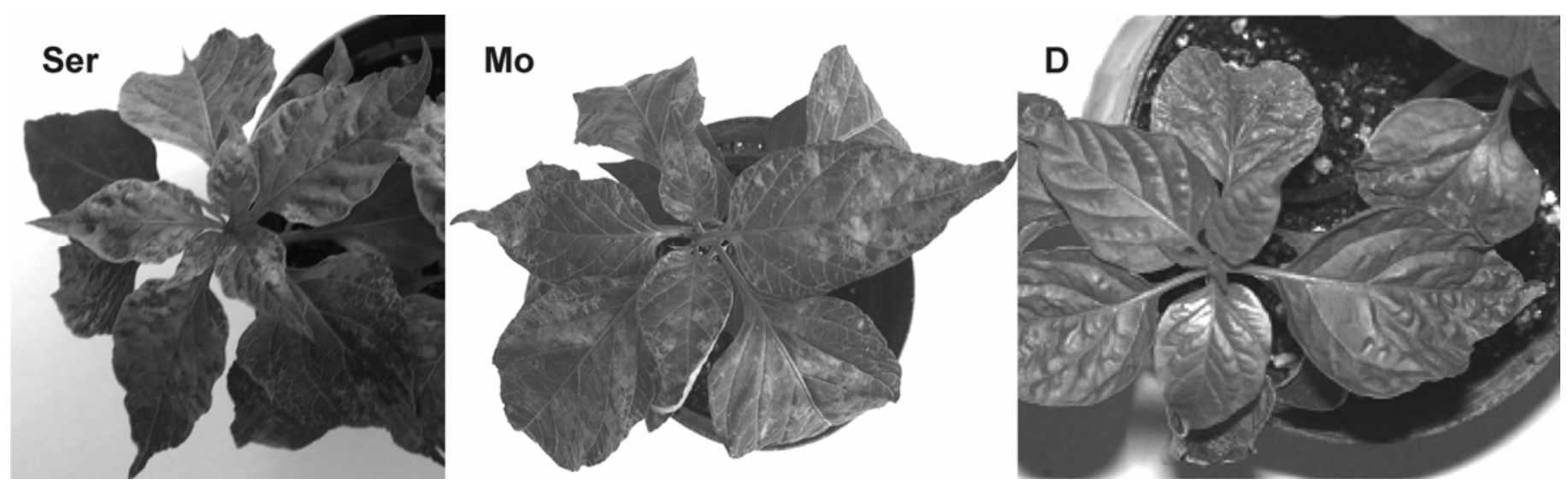

Fig. 4. Symptoms produced by three cloned Pepper golden mosaic virus (PepGMV) strains in pepper. Presented are images of Anaheim pepper plants 3 weeks after biolistic inoculation with cloned DNA components of PepGMV strains Serrano (Ser), mosaic (Mo), and distortion (D). Both Ser and Mo strains induced systemic mosaic but PepGMV-Ser induced a more chlorotic golden mosaic relative to the green-yellow mosaic caused by PepGMV-Mo. Leaf distortion and crumple symptoms produced by PepGMV-D were restricted to inoculated leaves. Pepper plants inoculated with PepGMV-D exhibited a recovery phenotype in which leaves developing after inoculation appeared symptomless.

TABLE 4. Symptom phenotypes of cloned Pepper golden mosaic virus (PepGMV) isolates -Ser, -Mo, and -D in four solanaceous hosts ${ }^{\mathrm{a}}$

\begin{tabular}{lcccc}
\hline PepGMV isolate & Datura stramonium & Pepper cv. Anaheim & Tobacco cv. Samsun & Tomato cv. Humava \\
\hline Ser & YeMo & YeMo, LC, VC & Mo, LC & Mo, LC \\
Mo & Mo, St VC & YeMo, LC, VC & MiMo, LC & MiMo, LC \\
D & St, LC, VC & LC, MiMo LD, R & MiMo, LC & Mo, LC \\
\hline
\end{tabular}

${ }^{\mathrm{a}} \mathrm{LC}=$ leaf curl, $\mathrm{LD}=$ leaf distortion, MiMo = mild mosaic, $\mathrm{Mo}=$ mosaic, $\mathrm{St}=$ stunting, YeMo $=$ yellow mosaic, $\mathrm{VC}=$ vein clearing, $\mathrm{R}=$ recovery with asymptomatic new growth.

TABLE 5. Whitefly transmission of progeny virus derived from cloned Pepper golden mosaic virus (PepGMV) isolates -Ser, -Mo, and - $\mathrm{D}^{\mathrm{a}}$

\begin{tabular}{lcccc}
\hline & \multicolumn{4}{c}{ Test plant infectivity } \\
\cline { 2 - 5 } Isolate & Source A & Source B & Source C & Source D \\
\hline Ser & $4 / 4$ & $4 / 4$ & $3 / 4$ & $3 / 4$ \\
Mo & $3 / 4$ & $4 / 5$ & $4 / 4$ & $3 / 4$ \\
D & $0 / 4$ & $0 / 4$ & $0 / 4$ & $0 / 4$ \\
\hline
\end{tabular}

${ }^{\mathrm{a}} \mathrm{B}$ biotype whiteflies given acquisition access to PepGMV-infected pepper (cv. Anaheim) source plants were transferred to four pepper test plants for inoculation access.

${ }^{b}$ Number of test plants infected/number of test plants inoculated.

nation of CR sequences, "captured" the heterologous PHYVVlike ancestral DNA-B. It is interesting to note that mixed infections of PepGMV and PHYVV can occur (21) and that the geographic distributions of the two viruses overlap (27). CaLCV, however, has a distinctly different host range and geographic distribution, suggesting that CaLCV has diverged from the common ancestor under significantly different conditions. In this scenario, subsequent divergence and adaptation for different hosts could have resulted in speciation of PepGMV and CaLCV from the common ancestor.

PepGMV is a bipartite begomovirus species with an extensive pool of genetic and phenotypic variation to draw from. Plant virologists commonly define virus strains based on relatively few examples isolated from nature and subsequently cultured under laboratory conditions. In a lab isolate, the cognate DNA components are isolated from other components of the same species and, as a result, their fates become absolutely linked due to a lack of alternatives. That all possible combinations of reassortants among the three isolates of PepGMV examined here were viable clearly indicates that different component combinations are possible. Given that begomoviruses do not cross-protect, mixed infections by several strains of a single virus may be a common event. Reassortment and segregation of different combinations of compatible components could occur easily following
TABLE 6. Pathogenicity of Pepper golden mosaic virus (PepGMV) reassortants derived from cloned components of PepGMV isolates -Ser, -Mo, and -D

\begin{tabular}{|c|c|c|c|}
\hline \multicolumn{2}{|c|}{ Inoculum source ${ }^{\mathrm{a}}$} & \multirow[b]{2}{*}{ Infectivity ${ }^{b}$} & \multirow[b]{2}{*}{ Symptom phenotype } \\
\hline DNA-A & DNA-B & & \\
\hline $\mathrm{D}$ & Mo & $15 / 16$ & YeMo, LC, VC \\
\hline $\mathrm{D}$ & Ser & $9 / 16$ & YeMo, LC, VC \\
\hline Mo & D & $13 / 16$ & LC, MiMo LDi, R \\
\hline Mo & Ser & $14 / 16$ & YeMo, LC, VC \\
\hline Ser & Mo & $13 / 16$ & YeMo, LC, VC \\
\hline Ser & D & $13 / 16$ & LC, MiMo LDi, R \\
\hline
\end{tabular}

${ }^{a}$ Cloned DNA of noncognate components of different isolates mixed and biolistically inoculated to pepper (cv. Anaheim) plants.

${ }^{b}$ Number of plants infected/number of plants inoculated. Data presented are for combined totals of four replicates with four plants per replicate.

${ }^{\mathrm{c}} \mathrm{LC}=$ leaf curl, $\mathrm{LDi}=$ leaf distortion, $\mathrm{MiMo}=$ mild mosaic, $\mathrm{Mo}=$ mosaic , YeMo = yellow mosaic, $\mathrm{VC}=$ vein clearing, $\mathrm{R}=$ recovery with asymptomatic new growth.

vector transmission, which may act as a severe bottleneck event, particularly when vector populations are low. In this way, bipartite begomoviruses may test the evolutionary fitness of different component pairs.

\section{ACKNOWLEDGMENTS}

Mention of proprietary or brand names are necessary to report factually on available data; however, the U.S. Department of Agriculture (USDA) neither guarantees nor warrants the standard of the product, and the use of the name by USDA implies no approval to the exclusion of others that also may be suitable.

\section{LITERATURE CITED}

1. Arguello-Astorga, G. R., Guevara-Gonzalez, R. G., Herrera-Estrella, L. R., and Rivera-Bustamante, R. F. 1994. Geminivirus replication origins have a group-specific organization of iterative elements: A model for replication. Virology 203:90-100.

2. Bird, J., and Maramorosch, K. 1978. Viruses and virus diseases associated with whiteflies. Adv. Virus Res. 22:55-110. 
3. Brown, J. K., and Bird, J. 1992. Whitefly-transmitted geminiviruses and associated disorders in the Americas and the Caribbean Basin. Plant Dis. 76:220-225.

4. Brown, J. K., Frolich, D. R., and Rosell, R. C. 1995. The sweet-potato or silverleaf whitefly-biotypes of Bemisia tabaci or a species complex. Annu. Rev. Entomol. 40:511-534.

5. Brown, J. K., Idris, A. M., and Fletcher, D. 1993. Sinaloa tomato leaf curl virus (STLCV), a new geminivirus of tomato and pepper in northwestern Mexico. Plant Dis. 77:1264.

6. Brown, J. K., and Nelson, M. R. 1988. Transmission, host range, and virus-vector relationships of chino del tomate virus, a whitefly-transmitted geminivirus from Sinaloa, Mexico. Plant Dis. 72:866-869.

7. Brown, J. K., Ostrow, K. M., Idris, A. M., and Stenger, D. C. 1999. Biotic, molecular, and phylogenetic characterization of bean calico mosaic virus, a distinct Begomovirus species with affiliation in the squash leaf curl virus cluster. Phytopathology 89:273-280.

8. Brown, J. K., Ostrow, K. M., Idris, A. M., and Stenger, D. C. 2000. Chino del tomate virus: Relationships to other begomoviruses and identification of A-component variants that affect symptom expression. Phytopathology 90:546-552.

9. Brown, J. K., and Poulos, B. T. 1990. Serrano golden mosaic virus: A newly identified whitefly-transmitted geminivirus of pepper and tomato in the United States and Mexico. Plant Dis. 74:720.

10. Brown, J. K., Poulos, B. T., and Nelson, M. R. 1989. Two whitefly-transmitted geminiviruses isolated form pepper affected with tigré disease. (Abstr.) Phytopathology 79:908.

11. Brown, J. K., Pozo-Campodonico, O., and Nelson, M. R. 1989. A whitefly-transmitted geminivirus from pepper with tigre disease. Plant Dis. 73:610.

12. Brown, J. K., and Ryan, R. 1991. High velocity microprojectile mediated transmission of whitefly-transmitted geminivirus DNA or purified virions to intact plants. (Abstr.) Phytopathology 81:1217.

13. Faria, J. C., Gilbertson, R. L., Hanson, S. F., Morales, F. J., Ahlquist, P., Loniello, A. O., and Maxwell, D. P. 1994. Bean golden mosaic geminivirus type II isolates from the Dominican Republic and Guatemala: Nucleotide sequences, infectious pseudorecombinants, and phylogenetic relationships. Phytopathology 84:321-329.

14. Fauquet, C. M., Bisaro, D. M., Briddon, R. W, Brown, J., Harrison, B. D., Rybicki, E. P., Stenger, D. C., and Stanley, J. 2003. Revision of taxonomic criteria for species demarcation in the family Geminiviridae, and an updated list of begomovirus species. Arch. Virol. 148:405-421.

15. Garzon-Tiznado, J. A., Torres-Pacheco, I., Ascencio-Ibanez, J. T., HerreraEstrella, L., and Rivera-Bustamante, R. F. 1993. Inoculation of peppers with infectious clones of a new geminivirus by a biolistic procedure. Phytopathology 83:514-521.

16. Gilbertson, R. L., Faria, J. C., Ahlquist, P., and Maxwell, D. P. 1993. Genetic diversity in geminiviruses causing bean golden mosaic disease: The nucleotide sequence of the infectious cloned DNA components of a
Brazilian isolate of bean golden mosaic geminivirus. Phytopathology 83:709-715.

17. Hou, Y. M, Garrido-Ramirez, E. R., Stingley, S., Guzman, P., and Gilbertson, R. L. 1996. Characterization of the infectious clones of the Sinaloa strain of pepper huasteco geminivirus. Plant Pathol. 86:S43.

18. Hou, Y.-M., and Gilbertson, R. L. 1996. Increased pathogenicity in a pseudorecombinant bipartite geminivirus correlates with intermolecular recombination. J. Virol. 70:5430-5436.

19. Idris, A. M., and Brown, J. K. 2004. Cotton leaf crumple virus is a distinct western hemisphere begomovirus species with complex evolutionary relationships indicative of recombination and reassortment. Phytopathology 94:1068-1074

20. Lokatrul, P., Valverde, R. A., De la Torre, R., and Sim, J. 2000. Occurrence of a strain of Texas pepper virus in tabasco and habanero pepper in Costa Rica. Plant Dis. 84:168-172.

21. Méndez-Lozano, J., Torres-Pacheco, I., Fauquet, C. M., and RiveraBustamante, R. F. 2003. Interactions between geminiviruses in a naturally occurring mixture: Pepper huasteco virus and Pepper golden mosaic virus. Phytopathology 93:270-277.

22. Padidam, M., Sawyer, S., and Fauquet, C. M. 1999. Possible emergence of new geminiviruses by frequent recombination. Virology 265:218-225.

23. Paplomatas, E. J., Patel, V. P., Hou, Y.-M., Noueiry, A. O., and Gilbertson, R. L. 1994. Molecular characterization of a new sap-transmissible bipartite genome geminivirus infecting tomatoes in Mexico. Phytopathology 84:1215-1224.

24. Stenger, D. C., Duffus, J. E., and Viallon, B. 1990. Biological and genomic properties of a geminivirus isolated from pepper. Phytopathology 80:704-709.

25. Swofford, D. L. 2001. PAUP*. Phylogenetic Analysis Using Parsimony (*and other methods). Version 4. Sinauer Associates, Sunderland, MA.

26. Thompson, J. D., Gibson, T. J., Plewniak, F., Jeanmougin, F., and Higgins, D. G. 1997. The CUSTALX windows interface: Flexible strategies for multiple sequence alignment aided by quality analysis tools. Nucleic Acid Res. 25:4876-4882.

27. Torres-Pacheco, I., Garzón-Tiznado, J. A., Brown, J. K., Becerra-Flora, A., and Rivera-Bustamante, R. F. 1996. Detection and distribution of geminiviruses in Mexico and the Southern United States. Phytopathology $86: 1186-1192$

28. Torres-Pacheco, I., Garzón-Tiznado, J. A., Herrera-Estrella, L., and Rivera-Bustamante, R. F. 1993. Complete nucleotide sequence of pepper huasteco virus: Analysis and comparison with bipartite geminiviruses. J. Gen. Virol. 74:2225-2231

29. Umaharan, P., Padidam, M., Phelps, R. H., Beachy, R. N., and Fauquet, C. M. 1998. Distribution and diversity of geminiviruses in Trinidad and Tobago. Phytopathology 88:1262-1268.

30. Wyatt, S. D., and Brown, J. K. 1996. Detection of subgroup III geminivirus isolates in leaf extracts by degenerate primers and polymerase chain reaction. Phytopathology 86:1288-1293. 